\title{
Health-seeking behaviour and student perception of health care services in a university community in Nigeria
}

\author{
M. O. Afolabi ${ }^{*}$, V. O. Daropale ${ }^{1}$, A. I. Irinoye ${ }^{2}$, A. A. Adegoke ${ }^{3}$ \\ ${ }^{1}$ Department of Clinical Pharmacy \& Pharmacy Administration, Faculty of Pharmacy, Obafemi Awolowo University, Ile-Ife, Nigeria; \\ *Corresponding Author: bunmafol@oauife.edu.ng, bunmafol@yahoo.com \\ ${ }^{2}$ Medical \& Health Services, Obafemi Awolowo University, Ile-Ife, Nigeria \\ ${ }^{3}$ Faculty of Social Sciences, Obafemi Awolowo University, Ile-Ife, Nigeria
}

Received 20 February 2013; revised 30 March 2013; accepted 16 April 2013

Copyright (c) 2013 M. O. Afolabi et al. This is an open access article distributed under the Creative Commons Attribution License, which permits unrestricted use, distribution, and reproduction in any medium, provided the original work is properly cited.

\section{ABSTRACT}

Objectives: Examining consumers' healthcare behavior can help in the design of ways to ensure better access to health and the quality of care. Health-seeking behavior is viewed as the varied response of individuals to states of illhealth, depending on their knowledge and perceptions of health, socioeconomic constraints, adequacy of available health services and attitude of healthcare providers. This study examines health-seeking behavior of university students, their use of healthcare services in the community and barriers to seeking help at the university health centre. Method: Structured questionnaires were validated and administered on a random sample of university students spread over different academic disciplines in a large institution. The sample consisted of 1608 undergraduate students attending the public university in southwestern Nigeria. The demographic profile reflects the national university student population. Relevant information was collected on preferred health services consulted by the undergraduates such as barriers to seeking adequate medical attention and their experiences with salient aspects of service delivery. Responses were weighted and the average was taken to be representative. Results: Students consulted their peers $(37.5 \%)$ in health related academic disciplines rather than seek treatment at the university health centre. Some students (24.7\%) preferred community pharmacies while others took personal responsibilities for their health or abstained from medical care for religious rea- sons (16.8\%). Significant barriers to seeking medical attention at the health centre were cost of care, protracted waiting time, inadequate health information, unfriendly attitude of healthcare workers and drug shortage. Conclusions: Students sought help from community pharmacies (ease of access) and from peers in health related academic programmes rather than from physicians at the health centre. Health-seeking behavior of the students was influenced, essentially, by the nature of ailment, waiting time in the health facility and attitude of healthcare professionals. Implications for policy, practice or delivery: The findings of this research identified the relative use of available health services within the university. Initiatives to improve student access to the university health centre should address significant barriers of patient delays, the need for attitudinal change and continuing professional development of relevant workers in the health facility. Promotional activities may be necessary to inform and educate students on rational use of medicines and access to treatment at the health centre.

Keywords: Health-Seeking Behaviour; Healthcare Services; University Health Centre

\section{INTRODUCTION}

Health-seeking behaviour has been defined as the activity undertaken by individuals who perceive themselves to have a health problem or to be ill for the purpose of finding an appropriate remedy [1]. Information of health seeking behaviour and health care utilisation 
has important policy implications in health system development. People seek help on health issues based on several reasons and the factors which influence the choice of treatment sources when symptoms occur include socio-cultural factors, social networks, gender and economic status. Access to healthcare facilities in terms of cost of treatment and healthcare provider attitude are also determinants of health seeking behaviour. There are indications that cost of prescribed medicines, poor access to facilities and patient delays affect the patronage and utilisation of public health services which increase the use of other treatment sources such as community pharmacies, drug peddlers, herbal medicine, religious or spiritual care organizations and students in health related academic disciplines [2].

Ill health is a major life event which may cause people to question their existence as this condition disrupts basic activities which are essential to a healthy living. Spirituality has been found to play a critical role in mitigating the pains and sufferings of ill-health because the relationship with a transcendent being or concept can give meaning and purpose to people's lives and sufferings. Several studies and surveys have demonstrated the relevance of spirituality in the health of patients [3,4].

Individuals differ in their choice of treatment sources depending on the type and perceived intensity of sickness; accessibility to the public health facility and demographic characteristics [5]. What people do when they have symptoms of illness has major implications for morbidity and progression of the illness and consequences for creating a healthy community. Delays or refusal in seeking and obtaining proper diagnosis and treatment can allow for a greater probability of adverse sequelae. Some studies have examined health-seeking behaviour in rural communities [6-9] but there has been no similar survey of healthcare preferences among student population in Nigeria. An understanding of healthseeking behavior of students in the university community is important if a healthy community is to be maintained. Apparently there are barriers to seeking appropriate healthcare at the university health centre for a number of reasons. Currently, there is neither empirical data on the level of patronage of alternative sources of healthcare in the university community nor the impact of service delivery on the utilisation of the organised healthcare facility. It is believed that such knowledge would assist the university authority in the management and development of accessible and effective healthcare services. The objectives of this study are to determine the level of patronage of healthcare facilities within the university community and to assess students' views of the services at the university health centre with a view to identifying possible barriers to effective utilisation of the institution's health facility. In this study, health-seeking behaviour is viewed as a tool for describing how individuals engaged with healthcare facilities within the university community.

\section{METHOD OF STUDY}

A sample of 1740 undergraduate students was selected by stratified random sampling from a population of 30,000 students in a large public university in Nigeria. A structured questionnaire was administered on the students at different times when they came for their classes. All the students who were present at the selected largely attended lecture periods were eligible to participate in the study, but only those who gave their consents constituted the sample. A total of 1608 duly completed questionnaire were returned representing $92.4 \%$ response rate. The questionnaire elicited information on the type of health services consulted by the undergraduate students, barriers to seeking medical attention at the university health centre and their perceptions of services at the delivery points. Collected data were analysed using descriptive statistics and SPSS (v.14). Due ethical approval was obtained from the Ethics and Research Committee of Obafemi Awolowo University Teaching Hospitals Complex, Ile-Ife.

\section{STUDY AREA}

The survey was conducted in Obafemi Awolowo University (OAU) Ile-Ife, one of the first generation universities in Nigeria. OAU, Ile-Ife was founded in 1962 and the university has a student population of about 30,000 students with nearly 24,000 as undergraduates. About $25 \%$ of students reside in the university hostels within the university community as at the time of this study. The university has a health centre located centrally on the campus and this primary healthcare centre has facilities for routine laboratory diagnosis, x-ray, physician consulting unit, pharmacy dept, nursing services, records department, wound dressing room and in-patient bed facilities for short term admissions. Other healthcare facilities within the university environment included a community pharmacy, patent medicine stores, religious organisations for spiritual care and alternative medicine itinerant sellers, all these were located in close proximity to the students' residential area.

\section{CONCEPTUAL FRAMEWORK}

The conceptual framework from a review on the determinants of health-seeking behavior served as basis for the questionnaire design $[1,10]$. The items were refined based on focus group interviews with four university faculty who were specialists in test measurement and evaluation. The questionnaire was pretested using 30 students from different academic programmes in the university and subsequently reviewed taking cognisance 
of the peculiar settings before data collection. The research instrument was then administered on consenting students across the sampled faculties. The final questionnaire consisted of both structured and open ended items to elicit information on relevant determinants of health-seeking behavior and perceptions of healthcare services in the institution. The focal indicators relevant to the purpose of this study included access to healthcare personnel, perceived quality of service, economic and socio-demographic factors. The socio-demographic data collected on the characteristics of respondents included sex, academic programme and religious belief. Data gathered on the physical access and quality of service included sources of healthcare in the university community and perceived quality of service at the university health centre, with emphasis on the availability of prescribed medicines, perceived competence of staff and their attitude and possible barriers to patronage of healthcare services at the health centre.

\section{STUDY DESIGN AND RESEARCH INSTRUMENT}

Questionnaire survey of a cross section of students in different academic programmes was carried out and focus group interviews conducted with purposively selected students accessing healthcare at the health centre. Structured multiple choice items were designed to yield scaled responses to the study items. Health-seeking behavior was measured by listing the questionnaire items and asking respondents to indicate level of agreement to perceived quality of care received from the health personnel, adequacy of infrastructure and access to the facility, using 5-point Likert scales (Strongly agree, Agree, Disagree, Strongly disagree and Can't say; (with scores of $4,3,2,1$ and 0 respectively). Furthermore, in an attempt to identify preferred sources of healthcare, respondents were asked to indicate the frequency of patronage from a list of some types of health facilities available in the university community. Similarly, the frequency of use was indicated on 5-point Likert scales (Every time, Very often, Often, Rarely and Never with values of 4, 3, 2, 1 and 0 respectively). Perceived barriers to the use of the health centre were measured using such indicators as waiting time, adequacy of health information, staff attitude, access to healthcare personnel and availability of prescribed medicines. Respondents were asked to indicate the extent to which some perceived barriers limited their utilisation of the institution's health centre (Every time, Very often, Often, Rarely, Never with values of 4, 3, 2, 1 and 0 respectively). The questionnaire solicited information on socio-demographic status, academic programme and religious beliefs of the students. Essentially, the questionnaire items were structured to determine the pattern of utilisation of available health- care services in the university; preferred sources of healthcare consulted by the students and possible barriers to effective utilisation of the health centre.

\section{SAMPLING AND DATA COLLECTION TECHNIQUES}

Undergraduate students of the university are required to take general elective courses in academic faculties other than their own and the classes for such electives are usually large and representative of students from different academic programmes. Three of such classes were targeted for the survey. Every student was eligible to be a part of the study. However, only those students who agreed to participate were enlisted to complete an anonymous, self-administered, structured item questionnaire conducted within a classroom setting and overseen by a research coordinator who had been trained on the questionnaire contents and administration. The questionnaire was administered on 1740 students in three major academic programmes of the university: Science and Technology, Humanities and Health Sciences.

\section{DATA ANALYSIS}

The collected data were analysed using SPSS v 14.0 software. Descriptive statistics were used to examine relative influence of the determinants of health-seeking behavior and utilisation of healthcare facilities in the community. Selected factors affecting health-seeking behaviour were ranked in order of importance and the weighted averages (WA) of the responses were computed to determine the level of agreement with the questionnaire items. Using the scoring of 0 to 4 on a 5-point Likert scale response mode, the deciding rule for the level of agreement was that any weighted average up to 2.50 or more was considered to be an agreement (A) with the questionnaire item while a value less than 2.50 was considered as a disagreement (D). Availability of health services was assessed by the degree of satisfaction with doctor's consultation and medicine supply in the pharmacy while the accessibility of service was determined by their perception of the attitude of health workers, operating hours and waiting time at the health facility.

\section{RESULTS}

The demographic distribution of respondents is shown in Table 1. A total of 1608 university undergraduates participated in this study out of which (51.4\%) were males and (48.6\%) were females. Further group differences include religious belief with Christians (86.6\%); Muslims (10.2\%) other religious faith (3.2\%). Respondents were categorised into three academic disciplines of Health Sciences: (17.5\%); Science \& Technology (17.8\%) and Humanities (64.7\%). Considering out-of-pocket ex- 
penses on healthcare, up to $60 \%$ of respondents spent less than 10 USD on medication in 4 months while only $3.9 \%$ spent more than 30 USD. The study showed that self treatment was the commonest form of care by respondents. The initial choice of care in ill health was self medication with medicines purchased over the counter or obtained through friends or neighbours. This was followed by visits to the health centre, patent medicine dealers, the community pharmacy, consultation with students in health related academic programmes and use of herbal remedies (Figure 1). Focus group interview indicated that the private health facilities were the initial choice of treatment for majority of students and the utilisation of university health centre was usually the last choice of care for reasons of excessive waiting time.

Table 2 shows the frequency of patronage of healthcare services available in the university community. A ranking of the responses based on the weighted average showed the community pharmacy as the most patronised followed by the doctor's clinic, while traditional healer was least patronised.

Table 3 shows the responses to salient aspects of healthcare services at the health centre and perceived barriers to utilisation of the facility. Based on the weighted average, the ranking showed that cost of care posed the highest barrier followed by protracted waiting time in the health facility but accessibility in terms of

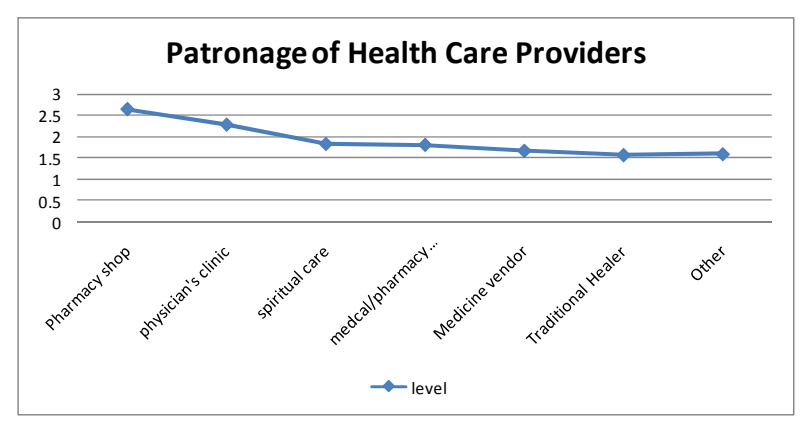

Figure 1. Patronage of health care providers.

Table 1. Demographic distribution of respondents.

\begin{tabular}{cccc}
\hline & Variables & No & $\%$ \\
\hline \multirow{2}{*}{ Gender } & Male & 827 & $51.4 \%$ \\
& Female & 781 & $48.6 \%$ \\
& Total & 1608 & \\
Religious & Christianity & 1393 & \\
belief & Islam & 164 & $86.6 \%$ \\
& Other religions & 52 & $10.2 \%$ \\
& Total & 1608 & $3.2 \%$ \\
Academic & Science \& Technology & 286 & \\
discipline & Humanities & 1040 & $17.5 \%$ \\
& Total & 1608 & $17.8 \%$ \\
\hline
\end{tabular}

location was not considered a barrier to patronage by the respondents.

Table 4 shows delay experiences at service delivery points in the health facility. The respondents experienced considerable delay at the doctor's clinic followed by delay period at the medical records but the nursing unit was considered to be relatively prompt in service delivery.

Respondents' perceptions of salient aspects of relevant services in different units of the university health centre are shown in Table 5. In the clinical services unit, appropriateness of diagnosis, patient waiting time, need for continuing professional development of the doctors and requirement for more experienced hands were ranked high, while in the pharmacy unit the 24-hour daily service was a welcome development but medicine supply appeared inadequate to meet patient needs. In the nursing unit, promptness of service delivery was recognised while services at the medical laboratory unit were inadequate. The survey showed that services at the medical records unit were not adequate and focus group interview agreed with this assertion. The file retrieval system was poor with excessive patient waiting time. Table 6 indicates the need to ease administrative bottleneck in each unit and for a re-organisation of the healthcare facility. Overall, submission of focus group interview was that patients were not satisfied with services rendered in the healthcare facility but these could be improved upon. This was also the submission of respondents from the questionnaire survey.

\section{DISCUSSION}

The findings of this study show that individuals differed in their choice of treatment sources depending on perceived severity of illness and accessibility of healthcare services. It was observed that more students would rather patronise the community pharmacies (33\%) than visit the university health centre (23.8\%), while a few students (6.85\%) patronised patent medicine vendors. Apparently the students were exposed to multiple sources of healthcare and they could switch among the alternatives sources depending on their perception of the intensity of illness. The results support the report of a similar study on healthcare switching behavior of patients with multiple sources of health care [7]. In cases of ill-health, a few students (11.1\%) preferred to consult with spiritual care before patronage of the health centre or community pharmacy, usually if the spiritual help fails to give an immediate relief. On the other hand, some of the respondents would not use any conventional medicine for religious reasons. Spirituality has been found to play a critical role in mitigating the pains and sufferings of ill-health, and this practice might be the reason for the choice of spiritual care by some respondents [3]. In fact, some authors have shown that many patients could be 
Table 2. Frequency of patronage of different types of healthcare services in the university.

\begin{tabular}{|c|c|c|c|c|c|c|}
\hline \multirow{4}{*}{$\begin{array}{l}\text { Types of health care } \\
\text { services } \\
\text { (score) } x\end{array}$} & \multicolumn{6}{|c|}{ Frequency of patronage } \\
\hline & \multirow{3}{*}{$\begin{array}{c}\text { Every } \\
\text { time } \\
4\end{array}$} & \multirow{3}{*}{$\begin{array}{c}\text { Very } \\
\text { often } \\
3\end{array}$} & \multirow{3}{*}{$\begin{array}{c}\text { Often } \\
2\end{array}$} & \multirow{3}{*}{$\begin{array}{l}\text { Rarely } \\
\qquad 1\end{array}$} & \multirow{3}{*}{$\begin{array}{c}\text { Never } \\
0 \\
0\end{array}$} & \multirow{3}{*}{ Weighted average } \\
\hline & & & & & & \\
\hline & & & & & & \\
\hline Doctor's f & 184 & 384 & 510 & 346 & 44 & 2.29 \\
\hline Clinic fx & 736 & 1152 & 1020 & 346 & 0 & \\
\hline Pharmacy f & 265 & 525 & 404 & 170 & 70 & 2.65 \\
\hline Shop fx & 1060 & 1575 & 808 & 170 & 0 & \\
\hline Patent $\mathrm{f}$ & 69 & 110 & 214 & 545 & 408 & 1.68 \\
\hline Medicine fx vendor & 276 & 330 & 428 & 545 & 0 & \\
\hline Traditional f & 56 & 92 & 211 & 613 & 390 & 1.58 \\
\hline Healer fx & 224 & 276 & 422 & 613 & 0 & \\
\hline Spiritual care (religious) f & 92 & 179 & 292 & 545 & 244 & \\
\hline fx & 368 & 537 & 584 & 545 & 0 & 1.84 \\
\hline Medical/Pharmacy f & 76 & 131 & 357 & 478 & 264 & \\
\hline Students fx & 304 & 393 & 714 & 478 & 0 & 1.81 \\
\hline Others $\mathrm{f}$ & 34 & 21 & 98 & 249 & 384 & 1.60 \\
\hline$f x$ & 136 & 63 & 196 & 249 & 0 & \\
\hline
\end{tabular}

Key: $\mathrm{f}$ = frequency of response; $\mathrm{x}$ = score of response.

Table 3. Perceived barriers to healthcare seeking at the University Health Centre.

\begin{tabular}{|c|c|c|c|c|c|c|}
\hline $\begin{array}{l}\text { Perceived } \\
\text { barriers } \\
\text { (score) x }\end{array}$ & $\begin{array}{c}\text { Every } \\
\text { time } \\
4\end{array}$ & $\begin{array}{l}\text { Very } \\
\text { often } \\
3\end{array}$ & Often & Rarely & Never & $\begin{array}{c}\text { Weighted } \\
\text { average }\end{array}$ \\
\hline Cost of care $\mathrm{f}$ & 274 & 406 & 303 & 269 & 162 & \multirow{2}{*}{2.55} \\
\hline fx & 1096 & 1218 & 606 & 269 & 0 & \\
\hline Waiting time $\mathrm{f}$ & 278 & 386 & 364 & 258 & 108 & \multirow{2}{*}{2.53} \\
\hline$f x$ & 1112 & 1158 & 728 & 258 & 0 & \\
\hline Lack sufficient Information f & 174 & 320 & 403 & 269 & 186 & \multirow{3}{*}{2.34} \\
\hline fx & 696 & 960 & 806 & 269 & 0 & \\
\hline Accessibility (distance) f & 138 & 210 & 399 & 393 & 214 & \\
\hline Attitude $\mathrm{f}$ & 290 & 288 & 341 & 317 & 126 & \multirow{3}{*}{2.45} \\
\hline (of workers) $\mathrm{fx}$ & 1160 & 864 & 682 & 317 & 0 & \\
\hline Medicines out of stock f & 164 & 322 & 391 & 317 & 156 & \\
\hline fx & 656 & 966 & 782 & 317 & 0 & 2.28 \\
\hline
\end{tabular}

Key: $\mathrm{f}$ = frequency of response; $\mathrm{x}=$ score of response.

helped by integrating religious practices or rituals in their care plan. [4] A few (3.55\%) of the respondents consulted traditional healers or sought herbal remedies for their ailments, while a few students (2.7\%) had never visited the health centre but would prefer to use over the counter medicines whenever they took ill. This choice 
Table 4. Delay experiences at service delivery points in the University Health Centre.

\begin{tabular}{|c|c|c|c|c|c|c|}
\hline \multirow{3}{*}{$\begin{array}{l}\text { Service delivery points } \\
\qquad \text { (score) } \mathrm{x}\end{array}$} & \multicolumn{6}{|c|}{ Delay experiences } \\
\hline & $\begin{array}{c}\text { Every } \\
\text { time }\end{array}$ & $\begin{array}{l}\text { Very } \\
\text { often }\end{array}$ & Often & Rarely & Never & Weighted average \\
\hline & 4 & 3 & 2 & 1 & 0 & \\
\hline Medical records f & 397 & 214 & 238 & 178 & 215 & \\
\hline fx & 1588 & 642 & 476 & 178 & 0 & 2.81 \\
\hline Doctor's clinic f & 391 & 312 & 250 & 171 & 156 & \\
\hline$f x$ & 1564 & 936 & 500 & 171 & 0 & 2.82 \\
\hline Pharmacy f & 172 & 204 & 232 & 346 & 262 & \\
\hline$f x$ & 688 & 612 & 464 & 346 & 0 & 2.21 \\
\hline Diagnostic Lab. f & 148 & 202 & 220 & 296 & 284 & \\
\hline fx & 592 & 606 & 440 & 296 & 0 & 2.23 \\
\hline Nursing unit $f$ & 96 & 168 & 184 & 379 & 353 & \\
\hline$f x$ & 384 & 504 & 368 & 379 & 0 & 2.0 \\
\hline
\end{tabular}

Key: $\mathrm{f}=$ frequency of response; $\mathrm{x}=$ score of response.

was probably borne out of delay experiences at the health centre and moreover, the alternative health care facilities appeared to be more accessible in terms of prompt service, friendly atmosphere and provision of required health information. Apparently, the students preferred the alternative sources of care with initial treatment options in a bid to minimise cost of care and to avoid delay experiences in the health facility.

Perceived barriers to adequate patronage of the health facility as highlighted by respondents were cost of care (25.2\%), excessive waiting time (24\%), lack of sufficient information on medicine use (19.9\%), poor attitude of health personnel (17.9\%) and shortage of prescribed medicines (20\%). These results agree with the findings of a previous study on possible barriers limiting patient access to healthcare services [8].

Patients experienced considerable delays at service delivery points of the health care facility, with long waits in doctors' consulting room and at the medical records unit. The promptness of nursing services was appreciated by a few respondents (34.4\%) and the file retrieval system at the medical records unit was considered inadequate (42.6\%), with the suggestions for a re-organisation or possible computerisation of processes in the unit. Apparently, patients were attended to in various units of the health facility with excessive waiting time and this resulted in dissatisfaction with the services. Previous studies have demonstrated that a patient's experience of waiting in a health system can radically influence his/her perceptions of service quality [11,12]. In fact, protracted waiting time has been given as a reason for not seeking care in some conventional health facilities [11].
Patient evaluation of the clinical services suggested a need for more experienced doctors (59\%) along with updates on continuing education for these healthcare professionals (51\%). On the other hand, respondents recognised the 24-hour daily services at the pharmacy unit (46.5\%) while the quality of medicine dispensed was appreciated (43.7\%). These observations are relevant in view of the literacy level of patrons of health services in the university community. The patients are probably better informed about their therapy and should be able to judge the technical quality of the care they receive. The findings in a previous study illustrated the importance of the level of patient education on perception of healthcare services and showed that patients with higher education could assess the competence of physicians and other health personnel more critically [13].

\section{CONCLUSION}

Factors preventing effective use of the university health centre include excessive waiting time at service delivery points and poor attitude of healthcare personnel; these issues should be addressed with a view to encouraging prompt health-seeking among the students. The personnel may need to show more empathy and understanding of patient sick role. The use of the health centre for proper diagnosis and consultation should be encouraged through appropriate information, education and communication. Restructuring of some of the service delivery points may be necessary, for instance, the pharmacy unit could have a private counseling unit to encourage patient disclosure. Decentralisation of the medical laboratory unit may be considered to facilitate 
Table 5. Respondents’ perception of service delivery points at the University Health Centre.

\begin{tabular}{|c|c|c|c|c|c|c|c|c|c|}
\hline \multirow{3}{*}{\multicolumn{2}{|c|}{$\begin{array}{c}\text { Service units } \\
\text { (score) }\end{array}$}} & \multicolumn{6}{|c|}{ Level of response } & \multirow{3}{*}{$\begin{array}{l}\text { Weighted } \\
\text { average/ } \\
\text { Rank }\end{array}$} & \multirow{3}{*}{ Decision } \\
\hline & & \multirow[b]{2}{*}{$\mathrm{x}$} & \multirow{2}{*}{$\begin{array}{c}\text { Strongly } \\
\text { agree } \\
4\end{array}$} & \multirow{2}{*}{$\begin{array}{c}\text { Agree } \\
3 \\
\end{array}$} & \multirow{2}{*}{$\begin{array}{c}\text { Disagree } \\
2 \\
\end{array}$} & \multirow{2}{*}{$\begin{array}{c}\text { Strongly } \\
\text { disagree } \\
1\end{array}$} & \multirow{2}{*}{$\begin{array}{c}\text { I can't say } \\
0\end{array}$} & & \\
\hline & & & & & & & & & \\
\hline \multicolumn{10}{|c|}{ Clinical Services } \\
\hline \multirow{2}{*}{1.} & \multirow{2}{*}{ Appropriate diagnosis of illness } & $\mathrm{f}$ & 226 & 693 & 138 & 54 & 376 & \multirow{2}{*}{$2.98 / 4$} & \multirow{2}{*}{ A } \\
\hline & & fx & 904 & 2074 & 276 & 54 & 0 & & \\
\hline \multirow{2}{*}{2.} & \multirow{2}{*}{ Personal choice of doctor to consult } & $\mathrm{f}$ & 92 & 244 & 532 & 155 & 451 & 27711 & $\mathrm{D}$ \\
\hline & & fx & 368 & 732 & 1064 & 155 & 0 & $2.2 / 111$ & D \\
\hline 3. & Consulting time with doctor is adequate & $\mathrm{f}$ & 140 & 408 & 348 & 156 & 402 & $2.51 / 10$ & A \\
\hline & 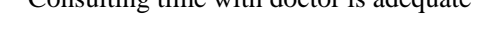 & fx & 560 & 1224 & 696 & 156 & 0 & $2.01 / 10$ & $\mathrm{~A}$ \\
\hline 4. & Doctors need continuing education & $\mathrm{f}$ & 391 & 428 & 192 & 64 & 387 & $307 / 2$ & A \\
\hline$\cdot$ & 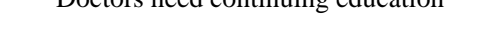 & fx & 1564 & 1284 & 384 & 64 & 0 & $3.0 / / 2$ & $\mathrm{~A}$ \\
\hline 5. & Need more experienced doctors & $\mathrm{f}$ & 503 & 446 & 106 & 78 & 317 & $321 / 1$ & A \\
\hline & 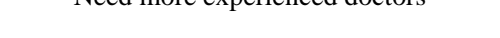 & fx & 2012 & 1338 & 212 & 78 & 0 & $0.21 / 1$ & $\Pi$ \\
\hline 6. & You can almost predict what the doctor will & $\mathrm{f}$ & 312 & 556 & 222 & 90 & 262 & $292 / 5$ & A \\
\hline 0. & prescription & fx & 1248 & 1668 & 444 & 90 & 0 & $2.92 / 5$ & $\mathrm{~A}$ \\
\hline 7 & Doctors' clinical judoment can be trusted & $\mathrm{f}$ & 168 & 591 & 217 & 106 & 368 & $276 / 7$ & $A$ \\
\hline 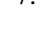 & 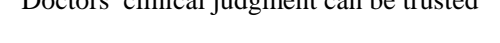 & fx & 672 & 1773 & 434 & 106 & 0 & $2.10 / 1 /$ & $\Lambda$ \\
\hline 8. & Doctors are annroachable & $\mathrm{f}$ & 172 & 601 & 220 & 127 & 320 & $273 / 8$ & A \\
\hline & Ducturs die appiodilidule & fx & 688 & 1803 & 440 & 127 & 0 & $2.10 / 0$ & 11 \\
\hline 9. & Excessive waiting time to see the doctor & $\mathrm{f}$ & 389 & 520 & 179 & 108 & 256 & $2.99 / 3$ & A \\
\hline 0. & 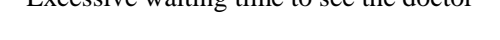 & fx & 1556 & 1560 & 358 & 108 & 0 & & \\
\hline 10. & Doctors consulting hours of service & $\mathrm{f}$ & 196 & 505 & 248 & 158 & 329 & $267 / 9$ & A \\
\hline & Acceptable & $f x$ & 784 & 1515 & 496 & 158 & 0 & $2.0 / 79$ & $\mathrm{~A}$ \\
\hline 11. & Difficult to see doctor at off peak period & $\mathrm{f}$ & 264 & 410 & 213 & 144 & 379 & $2.77 / 6$ & A \\
\hline 11. & Dinticuit to see coctor da ont peak period & $f x$ & 1056 & 1230 & 426 & 144 & 0 & $2.17 / 10$ & $\mathrm{~A}$ \\
\hline & & & Pharn & acy Ser & & & & & \\
\hline 1. & My medicine needs are met & $\mathrm{f}$ & 152 & 402 & 305 & 221 & 326 & $245 / 6$ & $\mathrm{D}$ \\
\hline & Miy medicine needs are met & fx & 608 & 1206 & 610 & 221 & 0 & $2.45 / 6$ & D \\
\hline 2. & Quality medicine dispensed & $\mathrm{f}$ & 212 & 491 & 201 & 172 & 332 & $2.69 / 3$ & A \\
\hline & & fx & 848 & 1473 & 402 & 172 & 0 & $2.007 \mathrm{~J}$ & $\Lambda$ \\
\hline 3. & 24-hour service is welcome & $\mathrm{f}$ & 290 & 458 & 150 & 182 & 324 & $279 / 1$ & A \\
\hline & & fx & 1160 & 1374 & 300 & 182 & 0 & $2 . / 31 \mathrm{t}$ & \\
\hline 4. & Pharmacy staff are courteous & $\mathrm{f}$ & 176 & 510 & 182 & 144 & 380 & $2.71 / 2$ & A \\
\hline & & fx & 704 & 1530 & 364 & 144 & 0 & & \\
\hline 5. & Waiting area at the pharmacy is convenient & $\mathrm{f}$ & 162 & 466 & 239 & 132 & 393 & $266 / 4$ & A \\
\hline & 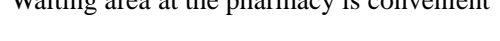 & fx & 648 & 1398 & 478 & 132 & 0 & $2.00 / 4$ & $\mathrm{~A}$ \\
\hline 6. & Pharmacy staff demonstrate competence & $\mathrm{f}$ & 130 & 494 & 230 & 168 & 360 & $257 / 5$ & A \\
\hline & Pilaninacy stant cemonistrate competerince & fx & 520 & 1482 & 460 & 168 & 0 & $2.5 / 10$ & $\mathrm{~A}$ \\
\hline & & & Nurs & ng Serv & & & & & \\
\hline 1. & Promptness of service & $\mathrm{f}$ & 128 & 425 & 239 & 206 & 402 & $2,48 / 3$ & $D$ \\
\hline & Promintiess or service & $f x$ & 512 & 1275 & 478 & 206 & 0 & $2.40 / 3$ & D \\
\hline 2. & Delav in administering injections & $\mathrm{f}$ & 158 & 317 & 249 & 178 & 482 & $2.50 / 2$ & A \\
\hline & & $f x$ & 632 & 951 & 498 & 178 & 0 & $2.50 / 2$ & A \\
\hline 3. & Courteous & $\mathrm{f}$ & 134 & 441 & 232 & 191 & 386 & $252 / 1$ & A \\
\hline & & $f x$ & 536 & 1323 & 464 & 191 & 0 & $2.52 / 1$ & A \\
\hline & & & Medical L & boratory & ervices & & & & \\
\hline & Service is adequate & $\mathrm{f}$ & 176 & 326 & 274 & 210 & 400 & $2.47 / 1$ & $\mathrm{D}$ \\
\hline & Seivice is duequate & fx & 704 & 978 & 548 & 210 & 0 & & D \\
\hline & & & Medical R & cords D & artment & & & & \\
\hline & Excessive waiting time & $\mathrm{f}$ & 298 & 393 & 228 & 114 & 357 & $285 / 1$ & A \\
\hline & Excessive walling tinle & $\mathrm{fx}$ & 1192 & 1179 & 456 & 114 & 0 & $2.03 / 1$ & $\mathrm{~A}$ \\
\hline & Retrieval (filing) system is not adequate & $\mathrm{f}$ & 282 & 403 & 196 & 116 & 387 & $285 / 1$ & $A$ \\
\hline & Ketrievar (ninng) system is not adequate & fx & 1128 & 1209 & 392 & 116 & 0 & $2.85 / 1$ & $\mathrm{~A}$ \\
\hline
\end{tabular}

Key: $\mathrm{f}$ = frequency of responses; $\mathrm{x}$ = score of responses; Respondents' decision: $\mathrm{A}=$ agreement; $\mathrm{D}$ = disagreement. 
Table 6. Respondents' general perception of service delivery points at the University Health Centre.

\begin{tabular}{|c|c|c|c|c|c|c|c|c|c|}
\hline & & & \multicolumn{5}{|c|}{ Level of response } & \multirow{3}{*}{$\begin{array}{c}\text { Weighted } \\
\text { average/ } \\
\text { Rank }\end{array}$} & \multirow{3}{*}{ Decision } \\
\hline & \multirow{2}{*}{\multicolumn{2}{|c|}{ (Score) $\mathrm{x}$}} & $\begin{array}{c}\text { Strongly } \\
\text { agree }\end{array}$ & Agree & Disagree & $\begin{array}{l}\text { Strongly } \\
\text { disagree }\end{array}$ & I can’t say & & \\
\hline & & & 4 & 3 & 2 & 1 & & & \\
\hline \multicolumn{10}{|c|}{ Comments } \\
\hline \multirow{2}{*}{1} & You need to know & $\mathrm{F}$ & 216 & 312 & 340 & 194 & 328 & \multirow{2}{*}{$2.52 / 3$} & \multirow{2}{*}{ A } \\
\hline & $\begin{array}{l}\text { someone ior prompt } \\
\text { action }\end{array}$ & $f x$ & 864 & 936 & 680 & 194 & 0 & & \\
\hline \multirow{2}{*}{2} & Poor administration of & $\mathrm{F}$ & 339 & 386 & 198 & 110 & 341 & \multirow{2}{*}{$2.92 / 2$} & \multirow{2}{*}{ A } \\
\hline & facility & fx & 1356 & 1158 & 396 & 110 & 0 & & \\
\hline \multirow{2}{*}{3} & Need to reorganise the & $\mathrm{F}$ & 329 & 450 & 188 & 96 & 321 & \multirow{2}{*}{$2.95 / 1$} & \multirow{2}{*}{ A } \\
\hline & departments & $f x$ & 1316 & 1350 & 376 & 96 & 0 & & \\
\hline \multirow{2}{*}{4} & Services are generally & $\mathrm{F}$ & 160 & 375 & 328 & 215 & 302 & \multirow{2}{*}{$2.45 / 4$} & \multirow{2}{*}{ D } \\
\hline & satisfactory & $f x$ & 640 & 1125 & 656 & 215 & 0 & & \\
\hline
\end{tabular}

Key: $\mathrm{f}$ = frequency of responses; $\mathrm{x}=$ score of responses; Respondents' decision: $\mathrm{A}$ = agreement; $\mathrm{D}$ = disagreement.

prompt and efficient services. This will enhance patronage, reduce morbidity and time loss from studies in illness, and enhance students' performance academically and physically. On the long run, prompt consultation at the onset of ill health will save costs in terms of reduced morbidity and mortality. In addition, computerisation of students' healthcare information will ease access to the records for further consultation and necessary follow-up. If these recommendations for restructuring and attitudinal change are effected, it is hoped that student patronage of the health centre facilities would improve.

\section{REFERENCES}

[1] MacKian, S. (2003) A review of health-seeking behaviour: Problems and prospects. Health Systems Development Programme, University of Manchester, Manchester.

[2] Ward, H., Mertens, T.E. and Thomas, C. (1997) Healthseeking behaviour and the control of sexually transmitted diseases. Health Policy and Planning, 12, 19-28. doi:10.1093/heapol/12.1.19

[3] Puchalski, C. and Sandoval, C. (2003) Spiritual care. In: O’Neill, J.F, Selwyn, P.A. and Schietinger, H.A., Eds., Clincal Guide to Supportive and Palliative Care for HIV/ AIDS Health Resources and Services Administration, US Department of Health and Human Services, 289-299.

[4] Puchalski, C.M. and Romer, A.L. (2000) Taking a spiritual history allows clinicians to understand patients more fully. Journal of Palliative Medicine, 3, 129-137. doi:10.1089/jpm.2000.3.129

[5] Haddad, S. and Fournier, P. (1995) Quality, cost and utilisation of health services in developing countries: A longitudinal study in Zaire. Social Science \& Medicine, 40,

\section{3-753. doi:10.1016/0277-9536(94)00134-F}

[6] Tones, K. (2004) Health promotion, health education and the public health. 4th Edition, Oxford Textbook of Public Health, Oxford University Press, Oxford, 82.

[7] Nyamonogo, I.K. (2002) Health care switching behaviour of malaria patients in a Kenyan rural community. Social Science \& Medicine, 54, 377-386. doi:10.1016/S0277-9536(01)00036-3

[8] Lasker, J.N. (1981) Choosing among therapies-Illness behaviour in the ivory coast. Social Science \& Medicine, 15A, 157-168.

[9] Jain, M., Nandan, D. and Misra, S.K. (2006) Qualitative assessment of health-seeking behaviour and perceptions regarding quality of health care services among rural community of district Agra. Indian Journal of Community Medicine, 31, 140-144.

[10] Uzochukwu, B.S. and Onwujekwe, O.E. (2004) Socioeconomic differences and health-seeking behavior for the diagnosis and treatment of malaria: A case study of four local government areas operating the Bamako initiative programme in south eastern Nigeria. International Journal for Equity in Health, 3, 6-20. doi:10.1186/1475-9276-3-6

[11] Afolabi, M.O. and Erhun, W.O. (2003) Patients response to waiting time in an out-patient pharmacy in Nigeria. Tropical Journal of Pharmaceutical Research, 2, 207-214.

[12] Dansky, K. and Miles, J. (1997) Patient satisfaction with ambulatory health care services: Waiting time and filling time. Hospital \& Health Services Administration, 42, 165177.

[13] Miseviciene, I. and Milasauskiene, Z. (2002) Patient satisfaction with the work of the hospital medical personnel. Medicina (Kaunas), 38, 559-565. 